Published in final edited form as:

Pediatr Blood Cancer. 2016 February ; 63(2): 326-333. doi:10.1002/pbc.25719.

\title{
Tobacco Use Among Siblings of Childhood Cancer Survivors: A Report from the Childhood Cancer Survivor Study
}

David Buchbinder, MD, MSHS ${ }^{1}$, Kevin Oeffinger, MD², Conrado Franco-Villalobos, BS, MS $^{3}$, Yutaka Yasui, $\mathrm{PhD}^{3}$, Melissa A. Alderfer, $\mathrm{PhD}^{4}$, Gregory T. Armstrong, $\mathrm{MD}^{5}$, Jacqueline Casillas, MD, MSHS ${ }^{6}$, Jennifer Ford, MD $^{2}$, Kevin R. Krull, PhD $^{5}$, Wendy Leisenring, PhD $^{7}$, Christopher Recklitis, PhD, $\mathrm{MPH}^{8}$, Leslie L. Robison, $\mathrm{PhD}^{5}$, Lonnie K. Zeltzer, $\mathrm{MD}^{6}$, and $\mathrm{E}$. Anne Lown, DrPH ${ }^{9}$

${ }^{1}$ Department of Pediatrics and Division of Hematology at Children's Hospital of Orange County, Orange, California

${ }^{2}$ Memorial Sloan-Kettering Cancer Center, New York, New York

${ }^{3}$ Department of Biostatistics, School of Public and Health, University of Alberta, Alberta, Canada

${ }^{4}$ Center for Healthcare Delivery Science, Nemours Children's Health System, Wilmington, DE \& Department of Pediatrics, Sidney Kimmel Medical College at Thomas Jefferson University, Philadelphia, PA

${ }^{5}$ Department of Epidemiology and Cancer Control, St. Jude Children's Research Hospital, Memphis, Tennessee

${ }^{6}$ David Geffen School of Medicine at University of California at Los Angeles (UCLA) and UCLA Jonsson Comprehensive Cancer Center, Los Angeles, California

${ }^{7}$ Cancer Prevention Program at Fred Hutchinson Cancer Research Center, Seattle, Washington

${ }^{8}$ Perini Family Survivors' Center, Dana-Farber Cancer Institute, Boston, Massachusetts

${ }^{9}$ Department of Social and Behavioral Sciences, University of California at San Francisco, San Francisco, California

\section{Abstract}

Background-Having a brother or sister with childhood cancer may influence health behaviors during adulthood. The aim of this study was to compare tobacco use in siblings of survivors with peers and to identify factors associated with sibling tobacco use.

Procedures-A retrospective cohort study was conducted using adult siblings $(\mathrm{N}=1,974)$ of 5+ year cancer survivors in the Childhood Cancer Survivor Study (CCSS) and participants $(\mathrm{N}=24,105$, weighted to match CCSS) in the 2007 National Health Interview Survey. Self-reported tobacco use, sociodemographic, and cancer-related risk factors were analyzed.

Corresponding author: David Buchbinder, MD, MSHS, CHOC Children's Hospital, 1201 W. La Veta Avenue, Orange, CA 92868, Phone 714-509-8459, Fax 714-509-8744, dbuchbinder@choc.org.

CONFLICT OF INTEREST STATEMENT

The authors have no conflicts of interest to declare. 
Results-Siblings were equally likely to have ever smoked compared to their peers, (Odds Ratio [OR] 1.02, 95\% Confidence Interval [CI] 0.93-1.12). Siblings were less likely to be current smokers (OR 0.83, 95\% CI 0.73-0.94), but more likely to be former smokers (OR 1.21, 95\% CI 1.08-1.35). Siblings with low education were more likely to ever smoke (OR 1.51, 95\% CI 1.152.00 ) and be current smokers (OR 1.67, 95\% CI 1.24-2.26) compared to their peers. Among siblings, risk factors for current tobacco use included: low income $<\$ 20,000$ (OR 1.66, 95\% CI 1.09-2.54), low education (OR 6.68, 95\% CI 4.07-10.97), psychological distress (OR 5.36, 95\% CI 2.21-13.02), and heavy alcohol use (OR 3.68, 95\% CI 2.50-5.41).

Conclusions-Siblings of survivors take up smoking at similar rates to their peers, but are more likely to quit. Efforts are needed to address disparities by providing greater psychosocial support and education for the lowest socio-economic status families facing childhood cancer.

\section{Keywords}

siblings; childhood cancer survivors; tobacco; smoking; health behavior

\section{INTRODUCTION}

Having a sibling with childhood cancer may influence psychological and behavioral outcomes in adulthood. Estimates suggest that there were over 420,000 survivors of childhood cancer in the United States (US) by the end of 2013 [1]. The National Cancer Institute, Office of Cancer Survivorship states that "family members, friends, and caregivers are part of the survivorship experience" [2]. With the excellent survival rate for childhood cancers and the average US family size of two children, [3] there is a large and growing population of siblings of childhood cancer survivors who continue to be impacted by the cancer experience long-term. Siblings disproportionately report impaired psychosocial health including post-traumatic stress reactions, psychological distress, and impairment in quality of life [4-7]. Despite the demonstration of sibling psychosocial impairment and the acknowledgement of the importance of characterizing the impact of the cancer experience on all family members, little is known about these siblings when they reach adulthood. Previous literature has reported higher risk for adverse health behaviors including heavy and risky alcohol use among siblings [8-9]. It is possible that the long and intensive treatment periods, characteristic for most childhood cancers, leave siblings with lower levels of adult supervision and support combined with higher levels of distress and family tension [7, 1012]. When treatment periods overlap a sibling's adolescence, typically a period of tobacco experimentation [13-15], risk for smoking may increase.

Tobacco use is an adverse health behavior that has been associated with significant morbidity and mortality, as well as an increased risk of cancer [16]. Smoking among siblings is cause for concern. Siblings of childhood cancer survivors are already at higher risk (standardized incidence ratio 1.5) of developing cancer compared to the general population [17]. Current smoking appears to be more common in adult siblings (31\%) compared to adult survivors (19\%) [18]. Separate data for same-aged peers from a national study show that $25 \%$ of youth smoked [19], but direct statistical comparisons have not been performed so we cannot definitely say whether siblings are smoking more than their peers. In another study of young male siblings, the same patterns emerged where siblings reported 
a higher prevalence of smoking compared to peers (36\% vs. 20\%) but again, direct statistical comparisons were not performed [20].

Sociodemographic risk factors for tobacco use have been identified in the general population [21-23]. Many of these risk factors and also cancer-related factors have been examined among cancer survivors as predictors of smoking. However, risk factors for smoking have not been examined for siblings of cancer survivors. Sociodemographic factors such as low income, low socioeconomic status and cancer-related factors including diagnosis, treatment intensity, and the presence of late effects may be associated with ongoing sibling distress and smoking [24].

The purpose of this study was to: (1) compare the tobacco use of siblings of childhood cancer survivors to that of the general population and, (2) identify demographic, health, and cancer-related factors associated with those behaviors. To accomplish this, we used data from the CCSS [25-26] along with comparison data from the National Health Interview (NHIS) survey [27]. We hypothesized that siblings of childhood cancer survivors would report increased tobacco use in comparison with the general population. Furthermore, we hypothesized that sibling demographic variables as well as survivor diagnosis, treatment intensity, and the presence of survivor late effects would be associated with increased tobacco use among siblings.

\section{METHODS}

\section{Childhood Cancer Survivor Study}

The CCSS is a retrospective cohort study of 5-year survivors of childhood cancer diagnosed between January 1, 1970 and December 31, 1986 and aggregated across 26 collaborating institutions in the US and Canada. A description of the study design, methods, and sample utilized by the CCSS has been published previously [25-26]. Eligibility criteria for the CCSS include: (1) a diagnosis of leukemia, central nervous system malignancy, Hodgkin lymphoma, non-Hodgkin lymphoma, kidney tumor, neuroblastoma, bone tumor, or soft tissue sarcoma prior to 21 years of age; and (2) survival to at least 5 years post-diagnosis. Figure 1 provides a flow diagram of sibling participants over three surveys showing an overall sibling participation rate of 59\%. Data for this study was collected from the fourth follow-up survey of the cohort; a 28-page self-report questionnaire. Completed by both survivors and their siblings, this follow-up questionnaire captured demographic information and information on physical and psychological health as well as health behaviors. Following consent, treatment data was obtained from the survivors' treating institution by trained medical record abstractors. The protocols and questionnaires underwent approval by the Institutional Review Boards of all collaborating centers and can be viewed at ccss.stjude.org.

\section{National Health Interview Survey}

As a comparison group, participants from the NHIS survey [27] were selected. The NHIS is an annual survey focused on the assessment of health in the US, which is conducted by the National Center for Health Statistics and the Center for Disease Control. The response rate was $78.3 \%$. A random sample of households within the United States is interviewed with 
respect to basic health and demographic characteristics utilizing a questionnaire. For the purpose of this study, data from the NHIS survey administered in 2007 was utilized. Tobacco use variables are closely comparable between the CCSS follow-up questionnaire and the NHIS survey, both administered in 2007 which included questions focusing on tobacco use.

\section{Primary Outcome Measures}

Tobacco Use Behaviors-Tobacco use behaviors were the primary outcome and included being a current smoker, former smoker, ever smoker, or never smoker. Being a current smoker was defined as those individuals that endorsed smoking cigarettes now. The two questions to assess this set of behaviors were similar between the CCSS and the NHIS as were response labels (CCSS: yes, no; NHIS: everyday, some days, not at all). NHIS responses were re-coded as a dichotomous outcome variable with current smokers reporting use everyday /some days versus non smokers who answered, "not at all". The CCSS followup questionnaire asked only about smoking in the past 2 years whereas the NHIS asked about lifetime smoking. To address the discrepancy in time frame supplemental data were used from siblings who participated in two previous CCSS surveys (baseline in 1995 and 2003) both of which asked about lifetime smoking to allow for the assessment of any smoking behavior over a 14 year period. Being a former smoker was defined for those who responded that they had smoked 100 cigarettes, but do not smoke currently. Ever smokers were defined as those who were current or former smokers. Never smokers were defined as those who denied smoking at least 100 cigarettes at the current and in all previous follow-up questionnaires (baseline or 2003).

\section{Independent Variables}

Sibling Factors-Sociodemographic, health, and cancer-related variables were assessed as potential risk factors for tobacco use among siblings. Sociodemographic factors included age at completion of the follow-up questionnaire, sex, race/ethnicity, educational attainment, and personal income. Sibling health-related factors included self-reported psychological health measured using the Brief Symptom Inventory 18 (BSI-18) [28-29] and general health using a five-category response scale: poor, fair, good, very good, and excellent. Sibling heavy alcohol use was also examined as a health-related risk factor and was defined as having 5 or more drinks daily for women and 6 or more drinks daily for men occurring at least once a month. Cancer-related factors included sibling age at diagnosis of the survivor's cancer and presence or absence of sibling bereavement (i.e., whether or not the survivor died following study entry).

Survivor Factors-Survivor health-related factors included self-reported general and psychological health measured as described above for siblings. Survivor tobacco use behaviors and heavy alcohol use were also defined as described above for siblings. Late adverse outcomes of cancer and its treatment included chronic health conditions, which were characterized according to the chronic health severity index derived from the NCI Common Terminology Criteria for Adverse Events [30]. Survivor cancer-related factors included diagnosis and treatment intensity as conceptualized previously using a yes/no composite variable of chemotherapy, surgery, and radiation therapy exposures [31]. 


\section{Statistical Analysis}

Data from the 1,974 siblings of the CCSS sample and 24,105 participants from the NHIS were analyzed. Descriptive statistics were generated for the sociodemographic, health, and cancer-related variables. Since income was missing in a large proportion of participants, we created a category of "missing income" in order to include them in our analyses: otherwise missing values were rare and participants with any missing value in variables used in an analysis were excluded from the analysis. The proportion of CCSS siblings and the proportion of NHIS participants reporting the tobacco use variables described above were calculated. Compared to the NHIS, CCSS siblings were younger, less racially/ethnically diverse, and of higher socioeconomic status (higher personal incomes and greater educational attainment). In order to address the sample differences, the NHIS data were weighted to reflect the distribution of CCSS siblings by age, race/ethnicity, personal income, and education.

Polytomous logistic regression was used to evaluate differences in tobacco use between CCSS siblings and NHIS participants across the four outcome categories: (1) never smoker; (2) former smoker; (3) current smoker; and (4) ever smoker. Descriptive statistics were used to characterize the samples on the examined risk factors for smoking including sex, race/ ethnicity (White, non-White), educational attainment (high school graduate yes, no), personal income $(>\$ 20,000 /$ year, $<\$ 20,000 /$ year), and age $(18-39,40+)$. Then, within the CCSS sibling sample, a polytomous logistic regression was used to assess risk factors for being current smokers and for being former smokers. The final model included all variables whose univariate $\mathrm{p}$-values were less than 0.20 . Odds ratios and their $95 \%$ confidence intervals were estimated. We used SAS version 9.4 (Cary, NC) and R 3.1.1 (Vienna, Austria) [R Core Team (2014). R: A language and environment for statistical computing. R Foundation for Statistical Computing, Vienna, Austria. URL http://www.R-project.org/] for the analyses.

\section{RESULTS}

Descriptive characteristics of the sibling CCSS and NHIS samples are provided in Table I. The median age at follow-up was 38 years (range $31-44$ years). The median age of the sibling at the time of cancer diagnosis was 8 years (range 3-14 years). There was a median interval of 28 years (range 25-32 years) between the time of the survivor's cancer diagnosis and the sibling's completion of the follow-up questionnaire. The CCSS siblings were younger than the NHIS participants (60\% in the 18-39 year age range versus $41 \%$ ). The CCSS sibling sample was composed of a greater proportion of White non-Hispanics (92\%) than the NHIS sample (70\%). Moreover, the CCSS siblings demonstrated greater educational attainment compared to NHIS participants, (88\% versus $54 \%$, respectively, with a high school education or greater).

\section{Tobacco Use: CCSS Siblings and the General Population}

Tables II and III provide data comparing tobacco use among the CCSS siblings and the NHIS participants. Overall, siblings were equally likely to have ever smoked compared to their peers, (OR 1.02, 95\% CI 0.93-1.12) but siblings (15.8\%) were significantly less likely 
(OR 0.83 , 95\% CI 0.73-0.94) to be current smokers compared with NHIS participants (19.2\%). The opposite finding was observed for former smoking (23.7\% of siblings, $19.8 \%$ of NHIS participants) (OR 1.21, 95\% CI 1.08-1.35) demonstrating greater likelihood of quitting smoking among siblings compared to their peers. In Table III, controlling for demographic differences between samples, siblings were less likely to be current smokers if they were young, male, white, having an income $>20,000$ or greater than a high school education. Siblings, compared to NHIS peers with the same characteristics, were more likely to be former smokers (ever smokers who quit) if they were young, white, low income or had greater than high school education. Finally, low education predicted greater likelihood of being an ever smoker with similar (but marginally significant) findings for the lowest income groups.

Figure 2 provides odds ratios for tobacco use among siblings compared to the NHIS participants, stratified by education, personal income, and age. CCSS siblings, compared to NHIS participants, who had not finished high school, were more likely to be current smokers compared to NHIS participants, with ORs ranging from 1.49 (95\% CI: 1.04-2.14) to 3.10 (95\% CI: 1.42-6.78) across income and age groups.

\section{Multivariable Analysis for Sibling Tobacco Use}

Table IV reports the multivariable analyses among siblings with respect to predictors of siblings' smoking status. Sibling sociodemographic factors associated with increased risk for current tobacco use included lower personal income and educational attainment. Siblings reporting a personal income of $<\$ 20,000$ had an increased risk $\left(\mathrm{OR}_{\mathrm{adj}} 1.66,95 \%\right.$ CI 1.09 2.54) of being a current smoker when compared to those siblings reporting a personal income of $>\$ 20,000$. Being a high school graduate or less was associated with greater risk $\left(\mathrm{OR}_{\mathrm{adj}} 6.68,95 \% \mathrm{CI} 4.07-10.97\right)$ of current smoking compared to siblings with more education. Sibling psychological distress $\left(\mathrm{OR}_{\mathrm{adj}} 5.36,95 \% \mathrm{CI} 2.21-13.02\right)$ and heavy alcohol use $\left(\mathrm{OR}_{\mathrm{adj}} 3.68,95 \%\right.$ CI 2.50-5.41) were associated with increased risk of current smoking.

Former smoking/or quitting once one has initiated smoking, was less likely for non-White siblings, $\left(\mathrm{OR}_{\mathrm{adj}} 0.39,95 \%\right.$ CI 0.19-0.82). Being a former smoker was more likely among siblings who reported heavy drinking, (OR adj 1.94, 95\% CI 1.41-2.67). Siblings who were older at diagnosis (i.e. $\geq 20$ years of age) were more likely to be former smokers, $\left(\mathrm{OR}_{\mathrm{adj}}\right.$ 5.79, 95\% CI 2.69-12.46) compared to unborn siblings at diagnosis. Siblings who were adolescents at the time of diagnosis were also more likely to become former smokers $(\mathrm{OR}=3.57,95 \%$ CI 1.84-6.91).

Survivor current $\left(\mathrm{OR}_{\mathrm{adj}} 3.87,95 \%\right.$ CI 2.34-6.41) and former tobacco use $\left(\mathrm{OR}_{\mathrm{adj}} 2.10,95 \%\right.$ CI 1.33-3.30) were both associated with current tobacco use among siblings. Survivor current ( $\left.\mathrm{OR}_{\mathrm{adj}} 2.01,95 \% \mathrm{CI} 1.26-3.18\right)$ and former tobacco use (OR $\mathrm{Odj}_{1.90,95 \%} \mathrm{CI} 1.34-$ 2.68) were both associated with former tobacco use among siblings. Other factors including survivor diagnosis, treatment intensity, adverse health, psychological distress, and chronic health conditions were not associated with current or former smoking among siblings. 


\section{DISCUSSION}

This is the first study of tobacco use behaviors among adult siblings of childhood cancer survivors to our knowledge. Overall, siblings were equally likely to have ever smoked, were less likely to be current smokers, and were more likely to be former smokers compared to the general population. In the sibling sample, those with fewer resources (less education, low income), more psychological distress, and those engaging in heavy drinking were most likely to be current smokers. Non-white siblings were less likely to quit smoking.

Findings from the present study document disparities in smoking patterns. Low education in siblings significantly increased the odds for current tobacco use compared to the general population. Among the sibling-only group the odds of being a former smoker was significantly lower in the non-white race/ethnicity group and current smoking was highest in the low income and low education groups. The higher prevalence of smoking and lower prevalence of quitters among low socioeconomic status groups is consistent with studies in the general population [32-33]. Our results suggest that adequate access to social, economic, and community resources for families impacted by childhood cancer may be particularly important for families with limited resources [34-35]. Hardships faced by families dealing with childhood cancer are enormous, but such hardships are even greater when a family has limited resources [36-37]. Greater resources may also be protective for other forms of substance use [38-39]. These results underscore the need to conduct regular assessments of family needs across the trajectory of cancer care with particular attention to the unique needs of siblings in order to limit adverse health behaviors and promote positive adaptation to the childhood cancer experience.

Sibling psychological distress was associated with higher risk for current tobacco use, consistent with previous research describing sibling psychological distress as a risk factor for heavy alcohol consumption among siblings [8-9]. The stress associated with the childhood cancer experience is significant [4-7] and such distress may have been associated with initiation of smoking, as well as with continued smoking into adulthood for some siblings. Sibling distress may be due to a variety of factors such as ongoing worry about the survivor, disrupted family roles, greater caregiver responsibilities, or feelings of isolation [7]. Siblings may attempt to regulate their mood and associated distress through tobacco use [40-41].

Older age of the sibling at the time of diagnosis was associated with being a former smoker. When the cancer treatment period overlaps adolescence, the peak period for the initiation of smoking [42], there may be increased likelihood that a sibling starts smoking. When adolescence coincides with parental preoccupation with the child with cancer and resulting decreased parental oversight, this group of siblings could be at higher risk for smoking. Early initiation of smoking is associated with difficulty quitting [43] and other long-term health and social problems [44].

Heavy alcohol use among siblings was associated with both current and former tobacco use among siblings echoing previous general population research [45]. This association may be due to genetic predisposition, environmental cues, or other psychosocial factors suggesting 
the need for smoking cessation programs that take into account previously described risks for smoking [46].

Tobacco use among survivors was associated with both current and former tobacco use among siblings. Previous research has documented greater tobacco use when role models are seen smoking [47]. Behaviors of the important people in the immediate environment of siblings whom they may look up to as role models are likely to influence the health behaviors of siblings. Survivor smoking may be related to modeling of parental or other family member's smoking, particularly in the face of stress. The characterization of responses to stress among family members as they relate to the practice of health risk behaviors may also be vital. Future studies must also incorporate parent and family-level data focusing on health behaviors of other family members in close proximity to siblings.

The increased risk for smoking among low socioeconomic status siblings and the decreased quitting among non-whites suggests a need to address the greater burden of childhood cancer in families who are faced with significant financial, educational, psychological, and social strains. Smoking cessation interventions should incorporate evidence-based practices combined with services to address specific hardships related to the cancer experience to promote positive adaptation [48-49]. Future studies should also identify how mental health and tobacco use are uniquely connected for siblings and how low socioeconomic status contributes to greater initiation of smoking, a trajectory of continued smoking, and reduced quitting. This research would provide new information to support the development of targeted interventions to limit health risk behaviors among siblings. Currently, the authors recommend increased screening, education, and follow-up by health care providers to prevent substance use among siblings [50].

When interpreting the results of our study, the following limitations should be considered. Differences exist between the CCSS and the NHIS; however, careful consideration was given to the accurate classification of the CCSS siblings with respect to smoking status. The sociodemographic characteristics of the CCSS cohort differed from the NHIS and sample and response rates among siblings were lower than among NHIS. These issues were addressed by weighting of the NHIS sample to reflect the sibling sample by age, race, personal income, and educational attainment. Next multivariate models controlled for factors such as age, sex, educational attainment, and personal income. This study makes unique contributions to the field documenting smoking history among the largest sample of siblings of long-term survivors of childhood cancer. Differing time frames for "ever" smoking between samples may result in conservative conclusions about having initiated smoking by siblings of cancer survivors compared to their peers.

In summary, siblings take up smoking at similar rates to the general population, and they appear to be more likely to quit smoking, however, subsets with lower socioeconomic status have greater risk for current smoking. Given the health consequences of tobacco use in this at-risk population, these data suggest a need to further characterize health behaviors including tobacco use among siblings of childhood cancer survivors. 


\section{ACKNOWLEDGEMENTS}

Work on this study was supported by a grant U24 CA55727 (GT Armstrong, Principal Investigator) from the National Cancer Institute, and by support to St. Jude Children's Research Hospital from the American Lebanese Syrian Associated Charities (ALSAC). The authors are grateful to the participants of the CCSS.

\section{REFERENCES}

1. Robison LL, Hudson MM. Survivors of childhood and adolescent cancer: life-long risks and responsibilities. Nat Rev Cancer. 2014; 14:61-70. [PubMed: 24304873]

2. About Cancer Survivorship Research: Survivorship Definitions. Retrieved August 8, 2009 from the National Cancer Institute Office of Cancer Survivorship Website: http:// cancercontrol.cancer.gov/ocs/definitions.html.

3. Current Population Survey Reports. Retrieved August 8, 2009 from the US Census Bureau Website: http://www.census.gov/population/www/socdemo/hh-fam.html.

4. Murray JS. Siblings of children with cancer: a review of the literature. J Pediatr Nurs. 1999; 16:2534.

5. Houtzager BA, Grootenhuis MA, Last BF. Adjustment of siblings to childhood cancer: a literature review. Support Care Cancer. 1999; 7:302-320. [PubMed: 10483815]

6. Wilkins KL, Woodgate RL. A Review of Qualitative Research on the Childhood Cancer Experience from the Perspective of Siblings: A Need to Give Them a Voice. J Pediatr Nurs. 2005; 22:305-319.

7. Alderfer MA, Long KA, Lown EA, Marsland AL, Ostrowski NL, Hock JM, Ewing LJ. Psychosocial adjustment of siblings of children with cancer: a systematic review. Psychooncology. 2010; 19:789805. [PubMed: 19862680]

8. Lown EA, Goldsby R, Mertens AC, Greenfield T, Bond J, Whitton J, Korcha R, Robison LL, Zeltzer LK. Alcohol consumption patterns and risk factors among childhood cancer survivors compared to siblings and general population peers. Addiction. 2008; 103:1139-1148. [PubMed: 18554347]

9. Lown EA, Mertens AC, Korcha RA, Leisenring W, Hudson MM, Greenfield TK, Robison LL, Zeltzer LK. Prevalence and predictors of risky and heavy alcohol consumption among adult siblings of childhood cancer survivors. Psychooncology. 2013; 22:1134-1143. [PubMed: 22736595]

10. Alderfer MA, Labay LE, Kazak AE. Brief report: does posttraumatic stress apply to siblings of childhood cancer survivors? J Pediatr Psychol. 2003; 28(4):281-286. [PubMed: 12730285]

11. Alderfer, MA.; Kazak, AE. Family issues when a child is on treatment for cancer. In: Brown, RA., editor. Pediatric Hematology/oncology: A biopspychosocial approach. New York: Oxford University Press; 2006.

12. Long KA, Marsland AL. Family Adjustment to Childhood Cancer: A Systematic Review. Clinical child and family psychology review. 2011

13. Kann L, Kinchen S, Shanklin SL, Flint KH, Kawkins J, Harris WA, Lowry R, Olsen EO, McManus T, Chyen D, Whittle L, Taylor E, Demissie Z, Brener N, Thornton J, Moore J, Zaza S. Centers for Disease Control and Prevention (CDC). Youth Risk Behavior Surveillance--United States, 2013. MMWR. Morbidity and mortality weekly report. 2014; 63(4):172.

14. Benjamin R. Preventing Tobacco Use among youth and young adults, A report of the Surgeon General. U.S. Department of Health and Human Services. 2012

15. Kroutil, L.; Colliver, J.; Gfroerer, J. OAS Data Review: Age and cohort patterns of substance use among adolescents. Rockville, MD: Substance Abuse and Mental Health Services Administration, Office of Applied Studies; 2010.

16. Balogh EP, Dresler C, Fleury ME, Gritz ER, Kean TJ, Myers ML, Nass SJ, Nevidjon B, Toll BA, Warren GW, Herbst RS. Reducing tobacco-related cancer incidence and mortality: summary of an institute of medicine workshop. Oncologist. 2014; 19:21-31. [PubMed: 24304712]

17. Friedman DL, Kadan-Lottick NS, Whitton J, Mertens AC, Yasui Y, Liu Y, Meadows AT, Robison LL, Strong LC. Increased Risk of Cancer among Siblings of Long-term Childhood Cancer Survivors: A Report from the Childhood Cancer Survivor Study. Cancer Epidemiol Biomarkers Prev. 2005; 14:1922-1927. [PubMed: 16103438] 
18. Tao ML, Zeltzer LK, Byrne J, Byrne J, Mills JL, Robison LL, Zeltzer LK. Smoking in Adult Survivors of Childhood Acute Lymphoblastic Leukemia. J Natl Cancer Inst. 1998; 90:219-225. [PubMed: 9462679]

19. National Center for Health Statistics. Health, United States, 2010: With Special Feature on Death and Dying. Hyattsville, MD: 2011.

20. Larcombe I, Mott M, Hunt L. Lifestyle behaviours of young adult survivors of childhood cancer. Br J Cancer. 2002; 87:1204-1209. [PubMed: 12439706]

21. Giovino GA. Epidemiology of tobacco use in the United States. Oncogene. 2002; 21:7326-7340. [PubMed: 12379876]

22. Trends in Tobacco Use. American Lung Association Research and Program Services Epidemiology and Statistics Unit July 2011. http://www.lung.org/finding-cures/our-research/trendreports/Tobacco-Trend-Report.pdf

23. The Epidemiology of Tobacco Use Among Young People in the United States and Worldwide. http://www.surgeongeneral.gov/library/reports/preventing-youth-tobacco-use/ sgr_2012_chapt3.pdf

24. Buchbinder D, Casillas J, Krull KR, Goodman P, Leisenring W, Recklitis C, Alderfer MA, Robison LL, Armstrong GT, Kunin-Batson A, Stuber M, Zeltzer LK. Psychological Outcomes of Siblings of Cancer Survivors: A Report from the Childhood Cancer Survivor Study. Psychooncology. 2011; 20:1259-1680. [PubMed: 22114043]

25. Robison LL, Mertens AC, Boice JD, Breslow NE, Donaldson SS, Green DM, Li FP, Meadows AT, Mulvihill JJ, Neglia JP, Nesbit ME, Packer RJ, Potter JD, Sklar CA, Smith MA, Stovall M, Strong LC, Yasui Y, Zeltzer LK. Study design and cohort characteristics of the Childhood Cancer Survivor Study: a multi-institutional collaborative project. Med Pediatr Oncol. 2002; 38:229-239. [PubMed: 11920786]

26. Robison LL, Armstrong GT, Boice JD, Chow EJ, Davies SM, Donaldson SS, Green DM, Hammond S, Meadows AT, Mertens AC, Mulvihill JJ, Nathan PC, Neglia JP, Packer RJ, Rajaraman P, Sklar CA, Stovall M, Strong LC, Yasui Y, Zeltzer LK. The Childhood Cancer Survivor Study: a National Cancer Institute-supported resource for outcome and intervention research. J Clin Oncol. 2009; 27:2308-2318. [PubMed: 19364948]

27. United States Department of Health and Human Services. Centers for Disease Control and Prevention. National Center for Health Statistics 2010, "National Health Interview Survey. 2007.

28. Derogatis LR. BSI 18 Brief Symptom Inventory 18, Administration, Scoring, and Procedures Manual. NCS Pearson. 2000

29. Recklitis CJ, Parsons SK, Shih MC, Mertens A, Robison LL, Zeltzer L. Factor structure of the brief symptom inventory--18 in adult survivors of childhood cancer: results from the childhood cancer survivor study. Psychol Assess. 2006; 18:22-32. [PubMed: 16594809]

30. Oeffinger KC, Mertens AC, Sklar CA, Kawashima T, Hudson MM, Meadows AT, Friedman DL, Marina N, Hobbie W, Kadan-Lottick NS, Schwartz CL, Leisenring W, Robison LL. Childhood Cancer Survivor Study. Chronic health conditions in adult survivors of childhood cancer. N Engl J Med. 2006; 355:1572-1582. [PubMed: 17035650]

31. Stuber ML, Meeske KA, Krull KR, Leisenring W, Stratton K, Kazak AE, Huber M, Zebrack B, Uijtdehaage SH, Mertens AC, Robison LL, Zeltzer LK. Prevalence and Predictors of Posttraumatic Stress Disorder in Adult Survivors of Childhood Cancer. Pediatrics. 2010; 125:e1124-e1134. [PubMed: 20435702]

32. Hiscock R, Bauld L, Amos A, Fidler JA, Munafò M. Socioeconomic status and smoking: a review. Ann N Y Acad Sci. 2012; 1248:107-123. [PubMed: 22092035]

33. Siahpush M, McNeill A, Borland R, Fong GT. Socioeconomic variation in nicotine dependence, self-efficacy, and intention to quit across four countries: findings from the International Tobacco Control (ITC) Four County Survey. Tob Control. 2006 Jun 15.(Suppl 3):iii71-iii75. [PubMed: 16754950]

34. Pachter LM, Auinger P, Palmer R, Weitzman M. Do parenting and the home environment, maternal depression, neighborhood, and chronic poverty affect child behavioral problems differently in different racial-ethnic groups? Pediatrics. 2006; 117(4):1329-1338. [PubMed: 16585331] 
35. Barrera M, Fleming CF, Khan FS. The role of emotional social support in the psychological adjustment of siblings of children with cancer. Child Care Health Dev. 2004; 30(2):103-111. [PubMed: 14961863]

36. Meeske KA, Patel SK, Palmer SN, Nelson MB, Parow AM. Factors associated with health-related quality of life in pediatric cancer survivors. Pediatr Blood Cancer. 2007; 49(3):298-305. [PubMed: 16779805]

37. Yallop K, McDowell H, Koziol-McLain J, Reed PW. Self-reported psychosocial wellbeing of adolescent childhood cancer survivors. Eur J Oncol Nurs. 2013; 17(6):711-719. [PubMed: 23891387]

38. Wills TA, Vaccaro D, McNamara G. The role of life events, family support, and competence in adolescent substance use: a test of vulnerability and protective factors. Am J Community Psychol. 1992; 20(3):349-374. [PubMed: 1415032]

39. Mason MJ, Mennis J, Schmidt CD. A social operational model of urban adolescents' tobacco and substance use: a mediational analysis. J Adolesc. 2011; 34(5):1055-1063. [PubMed: 21144577]

40. Geller AC, Emmons K, Brooks DR, Zhang Z, Powers C, Koh HK, Sober AJ, Miller DR, Li F, Haluska F, Gilchrest BA. Skin cancer prevention and detection among siblings of patients with melanoma. J Am Acad Dermatology. 2003; 49:631-638.

41. Conrad M, Wardie M, King A, de Wit H. Relationship of self-reported and acute stress to smoking in emerging adult smokers. J Clin Psychol. 2013; 69:710-717. [PubMed: 23280768]

42. Department of Health and Human Services (US) Atlanta: HHS, Centers for Disease Control and Prevention, National Center for Chronic Disease Prevention and Health Promotion, Office on Smoking and Health (US); 2012. [cited 2014 Dec 30]. Preventing tobacco use among youth and young adults: a report of the Surgeon General.

43. Grant BF, Dawson DA. Age at onset of alcohol use and its association with DSM-IV alcohol abuse and dependence: results from the National Longitudinal Alcohol Epidemiologic Survey. J Subst Abuse. 1997; 9:103-110. [PubMed: 9494942]

44. Brown SA, McGue M, Maggs J, Schulenberg J, Hingson R, Swartzwelder S, Martin C, Chung T, Tapert SF, Sher K, Winters KC, Lowman C, Murphy S. A developmental perspective on alcohol and youths 16 to 20 years of age. Pediatrics. 2008; 121(Suppl 4):S290-S310. [PubMed: 18381495]

45. Falk DE, Yi HY, Hiller-Sturmhofel S. An epidemiologic analysis of co-occurring alcohol and tobacco use and disorders: findings from the National Epidemiologic Survey on Alcohol and Related Conditions. Alcohol Res Health. 2006; 29:162-171. [PubMed: 17373404]

46. Young SE, Rhee SH, Stallings MC, Corley RP, Hewitt JK. Genetic and environmental vulnerabilities underlying adolescent substance use and problem use: general or specific? Behav Genet. 2006; 36:603-615. [PubMed: 16619135]

47. Tyas SL, Pederson LL. Psychosocial factors related to adolescent smoking: a critical review of the literature. Tob Control. 1998; 7(4):409-420. [PubMed: 10093176]

48. Draft Recommendation Statement: Tobacco Smoking Cessation in Adults and Pregnant Women: Behavioral and Pharmacotherapy Interventions. U.S. Preventive Services Task Force. 2015 May.

49. Milton MH, Maule CO, Backinger CL, Gregory DM. Recommendations and guidance for practice in youth tobacco cessation. Am J Health Behav. 2003; 27(Suppl 2):S159-S169. [PubMed: 14521243]

50. Fiore MC, Jaen CR, Baker TB, Bailey WC, Bennett G, Benowitz NL, Christiansen BA, Connell M, Curry SJ, Dorfman SF, Fraser D, Froelicher ES, Goldstein MG, Hasselblad V, Healton CG, Heishman S, Henderson PN, Heyman RB, Husten C, Koh HK, Kottke TE, Lando HA, Leitzke C, Mecklenburg RE, Mermelstein RJ, Morgan G, Mullen PD, Murray EW, Orleans CT, Piper ME, Robinson L, Stitzer ML, Theobald W, Tommasello AC, Villejo L, Wewers ME, Williams C. A clinical practice guideline for treating tobacco use and dependence: 2008 update. A U.S. Public Health Service report. Am J Prev Med. 2008; 35(2):158-176. [PubMed: 18617085] 


\section{4,828 Participating siblings}

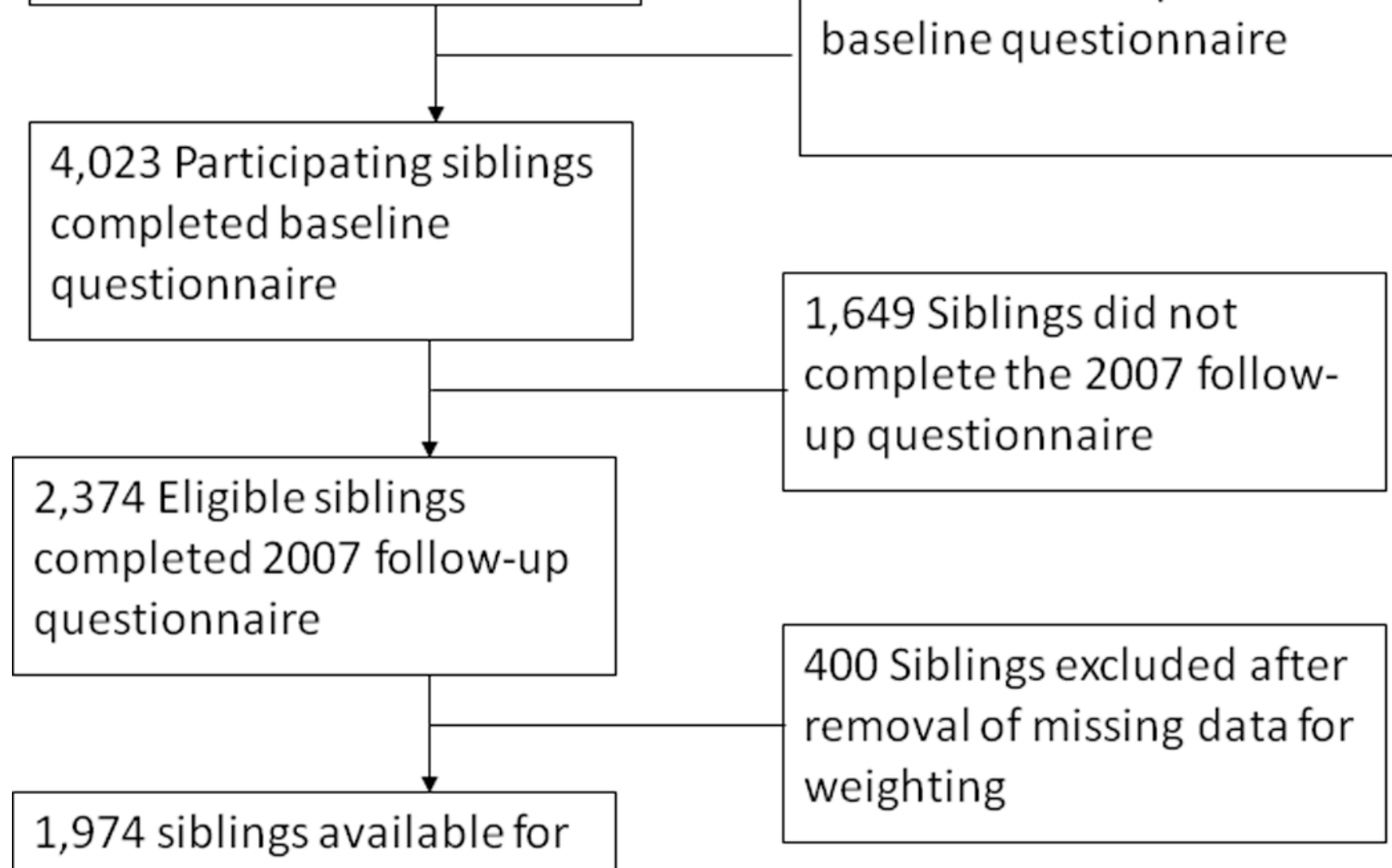
analysis

Figure 1.

Flow diagram of CCSS sibling participants 


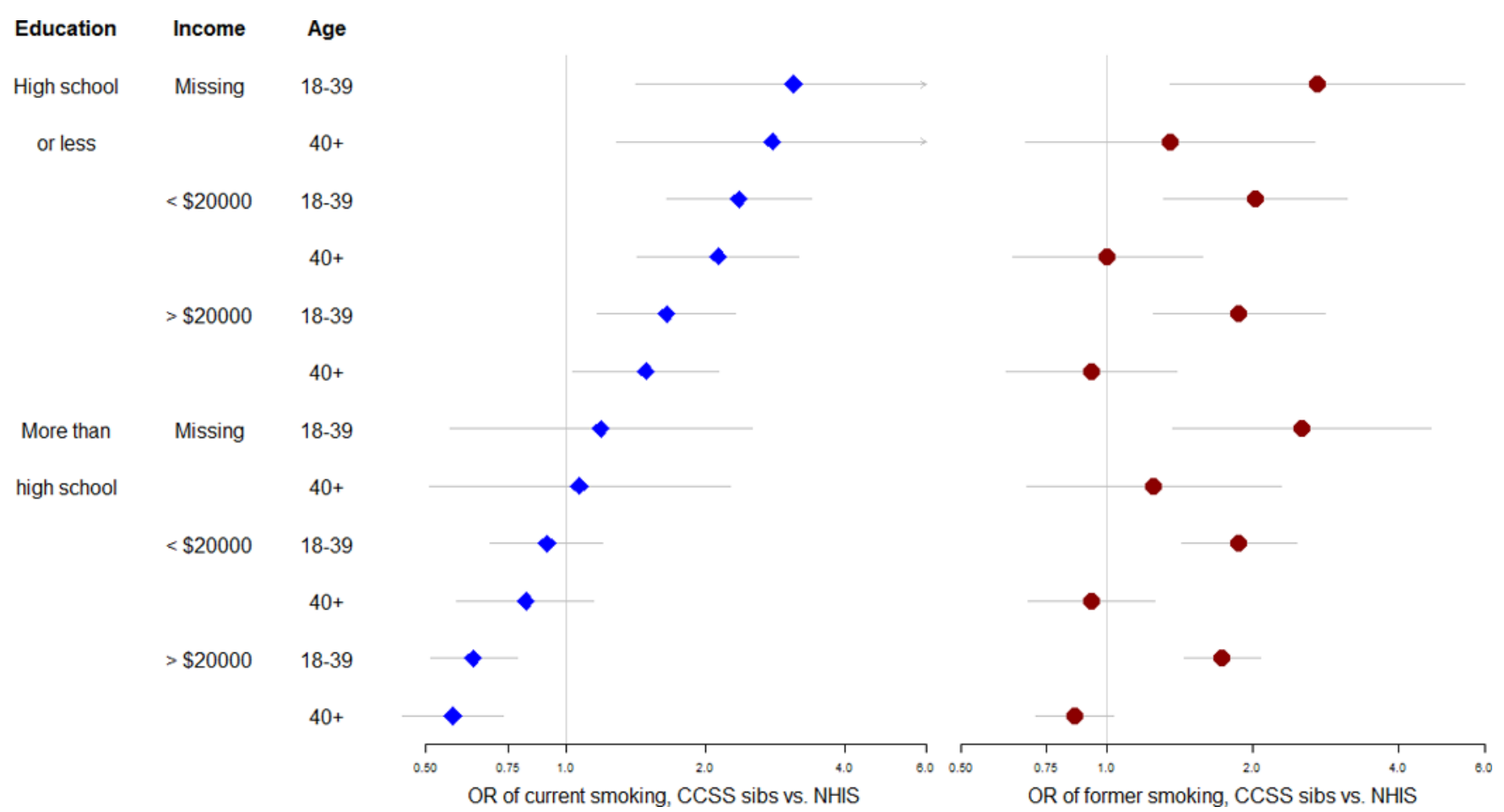

Figure 2.

Sex and race/ethnicity-adjusted current and former smoking odds ratios for CCSS siblings compared to their NHIS peers. 


\section{Table I}

Characteristics of the CCSS sibling population and the participants from the NHIS

\begin{tabular}{|c|c|c|c|c|}
\hline & \multicolumn{2}{|c|}{$\begin{array}{c}\text { CCSS Siblings } \\
(\mathbf{N}=1,974)\end{array}$} & \multicolumn{2}{|c|}{ NHIS $(\mathrm{N}=\mathbf{2 4 , 0 5 6})$} \\
\hline & Frequency & Percent & Frequency & Percent \\
\hline \multicolumn{5}{|l|}{ Age at Interview } \\
\hline $18-39$ years & 1,175 & 59.5 & 9,743 & 40.5 \\
\hline$\geq 40$ years & 799 & 40.5 & 14,313 & 59.5 \\
\hline \multicolumn{5}{|l|}{ Sex } \\
\hline Female & 1,065 & 54.0 & 13,223 & 55.0 \\
\hline Male & 909 & 46.0 & 10,833 & 45.0 \\
\hline \multicolumn{5}{|l|}{ Race/Ethnicity } \\
\hline Other & 150 & 7.6 & 7,148 & 29.7 \\
\hline White non-Hispanic & 1,824 & 92.4 & 16,908 & 70.3 \\
\hline \multicolumn{5}{|l|}{ Personal Income } \\
\hline $0-\$ 19,999$ & 477 & 24.2 & 4,412 & 18.3 \\
\hline$\geq \$ 20,000$ & 1,438 & 72.8 & 8,286 & 34.5 \\
\hline Missing & 59 & 3.0 & 11,358 & 47.2 \\
\hline \multicolumn{5}{|l|}{ Education } \\
\hline High School Graduate or Less & 230 & 11.7 & 10,981 & 45.7 \\
\hline Greater than High School & 1,744 & 88.3 & 13,075 & 54.3 \\
\hline \multicolumn{5}{|l|}{ Survivor Diagnosis } \\
\hline Leukemia & 794 & 33.5 & & \\
\hline Central Nervous System & 301 & 12.7 & & \\
\hline Hodgkin Disease & 336 & 14.2 & & \\
\hline Non-Hodgkin Lymphoma & 192 & 8.1 & & \\
\hline Kidney & 200 & 8.4 & & \\
\hline Neuroblastoma & 148 & 6.2 & & \\
\hline Soft Tissue Sarcoma & 221 & 9.3 & & \\
\hline Bone Cancer & 178 & 7.5 & & \\
\hline
\end{tabular}




\section{Table III}

Predicting Tobacco use behaviors of the CCSS sibling population vs. NHIS participants*

\begin{tabular}{|c|c|c|c|}
\hline & Current Smoker & Former Smoker & Ever Smoker \\
\hline & OR $(95 \% \mathrm{CI})$ & OR $(95 \% \mathrm{CI})$ & OR $(95 \% \mathrm{CI})$ \\
\hline Overall & $0.83(0.73-0.94)^{* *}$ & $1.21(1.08-1.35)^{* *}$ & $1.02(0.93-1.12)$ \\
\hline \multicolumn{4}{|l|}{ Age at follow-up } \\
\hline $18-39$ years & $0.84(0.72-0.99)^{* *}$ & $1.43(1.23-1.67)^{* *}$ & $1.09(0.96-1.23)$ \\
\hline$\geq 40$ years & $0.81(0.65-1.00)$ & $1.01(0.86-1.19)$ & $0.94(0.81-1.08)$ \\
\hline \multicolumn{4}{|l|}{ Sex } \\
\hline Female & $0.86(0.72-1.03)$ & $1.21(1.04-1.40)^{* *}$ & $1.04(0.91-1.18)$ \\
\hline Male & $0.80(0.67-0.97)^{* *}$ & $1.21(1.03-1.42)^{* *}$ & $1.00(0.87-1.15)$ \\
\hline \multicolumn{4}{|l|}{ Race/Ethnicity } \\
\hline Other & $1.07(0.66-1.74)$ & $1.44(0.88-2.35)$ & $1.22(0.85-1.78)$ \\
\hline White non-Hispanic & $0.82(0.71-0.93)^{* *}$ & $1.20(1.07-1.34)^{* *}$ & $1.01(0.92-1.11)$ \\
\hline \multicolumn{4}{|l|}{ Personal Income } \\
\hline $0-\$ 19,999$ & $1.08(0.86-1.37)$ & $1.41(1.10-1.80)^{* *}$ & $1.21(1.00-1.46)$ \\
\hline$\geq \$ 20,000$ & $0.72(0.62-0.85)^{* *}$ & $1.14(1.00-1.30)$ & $0.95(0.85-1.06)$ \\
\hline \multicolumn{4}{|l|}{ Education } \\
\hline High School Graduate or Less & $1.67(1.24-2.26)^{* *}$ & $1.22(0.84-1.80)$ & $1.51(1.15-2.00)^{* *}$ \\
\hline Greater than High School & $0.69(0.59-0.80)^{* *}$ & $1.21(1.07-1.36)^{* *}$ & $0.97(0.88-1.07)$ \\
\hline
\end{tabular}

*NHIS data were weighted to reflect the distribution of CCSS siblings by age, race/ethnicity, personal income, and education ** $\mathrm{p}<0.05$ 
Table IV

Multivariable Models For CCSS Sibling Tobacco Use

\begin{tabular}{|c|c|c|}
\hline & Current Smoker vs. Never Smoker & Former Smoker vs. Never Smoker \\
\hline Sibling and Survivor Factors & OR $(95 \% \mathrm{CI})$ & OR $(95 \% \mathrm{CI})$ \\
\hline \multicolumn{3}{|l|}{ Age at Interview } \\
\hline $18-39$ years & $1.07(0.63-1.83)$ & $0.94(0.63-1.38)$ \\
\hline$\geq 40$ years (referent) & 1.00 & 1.00 \\
\hline \multicolumn{3}{|l|}{ Sex } \\
\hline Male & $1.03(0.70-1.50)$ & $1.16(0.86-1.56)$ \\
\hline Female (referent) & 1.00 & 1.00 \\
\hline \multicolumn{3}{|l|}{ Race/Ethnicity } \\
\hline Other & $0.67(0.31-1.42)$ & $0.39(0.19-0.82)^{* *}$ \\
\hline White non-Hispanic (referent) & 1.00 & 1.00 \\
\hline \multicolumn{3}{|l|}{ Household Income } \\
\hline Missing & $2.25(0.91-5.58)$ & $1.43(0.65-3.14)$ \\
\hline $0-\$ 19,999$ & $1.66(1.09-2.54)^{* *}$ & $1.12(0.77-1.62)$ \\
\hline$\geq \$ 20,000$ & 1.00 & 1.00 \\
\hline \multicolumn{3}{|l|}{ Education } \\
\hline High School Graduate or Less & $6.68(4.07-10.97)^{* *}$ & $1.63(0.95-2.79)$ \\
\hline Greater than High School (referent) & 1.00 & 1.00 \\
\hline \multicolumn{3}{|l|}{ Sibling Health } \\
\hline Fair / Poor & $1.35(0.60-2.99)$ & $0.75(0.35-1.61)$ \\
\hline Excellent / Very Good / Good (referent) & 1.00 & 1.00 \\
\hline \multicolumn{3}{|l|}{ Sibling Heavy Alcohol Use } \\
\hline Yes & $3.68(2.50-5.41)^{* *}$ & $1.94(1.41-2.67)^{* *}$ \\
\hline No (referent) & 1.00 & 1.00 \\
\hline \multicolumn{3}{|l|}{ Sibling Psychological Distress } \\
\hline Yes & $5.36(2.21-13.02)^{* *}$ & $1.44(0.52-3.98)$ \\
\hline No (referent) & 1.00 & 1.00 \\
\hline \multicolumn{3}{|l|}{ Sibling Age at Diagnosis } \\
\hline $0-10$ years & $1.26(0.77-2.08)$ & $2.28(1.37-3.80)^{* *}$ \\
\hline $10-14$ years & $1.00(0.51-1.95)$ & $2.93(1.62-5.30)^{* *}$ \\
\hline $15-19$ years & $0.86(0.38-1.93)$ & $3.57(1.84-6.91)^{* *}$ \\
\hline $20+$ years & $1.32(0.48-3.61)$ & $5.79(2.69-12.46)^{* *}$ \\
\hline Not born yet (referent) & 1.00 & 1.00 \\
\hline \multicolumn{3}{|l|}{ Survivor Heavy Alcohol Use } \\
\hline Yes & $0.91(0.60-1.37)$ & $0.84(0.60-1.17)$ \\
\hline No (referent) & 1.00 & 1.00 \\
\hline Survivor Psychological Distress ${ }^{\#}$ & & \\
\hline
\end{tabular}

Pediatr Blood Cancer. Author manuscript; available in PMC 2017 February 01. 


\begin{tabular}{|c|c|c|c|}
\hline \multirow{11}{*}{ 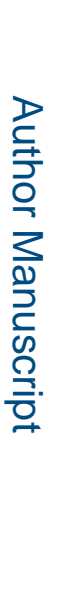 } & & Current Smoker vs. Never Smoker & Former Smoker vs. Never Smoker \\
\hline & Sibling and Survivor Factors & OR $(95 \% \mathrm{CI})$ & OR $(95 \% \mathrm{CI})$ \\
\hline & Yes & $0.62(0.24-1.65)$ & $1.48(0.77-2.86)$ \\
\hline & No (referent) & 1.00 & 1.00 \\
\hline & Survivor Tobacco Use & & \\
\hline & Current Smoker & $3.87(2.34-6.41)^{* *}$ & $2.01(1.26-3.18)^{* *}$ \\
\hline & Former Smoker & $2.10(1.33-3.30)^{* *}$ & $1.90(1.34-2.68)^{* *}$ \\
\hline & Never Smoker (referent) & 1.00 & 1.00 \\
\hline & Survivor Chronic Health Conditions & & \\
\hline & Yes & $1.17(0.80-1.71)$ & $0.74(0.55-1.01)$ \\
\hline & No (referent) & 1.00 & 1.00 \\
\hline
\end{tabular}

\# Psychological Distress= GSI for the outcome of psychological distress.

**

$\mathrm{p}<0.05$ 